Fd Cosmet. Toxicol. Vol. 6, pp. 261-269. Pergamon Prcss 1968. Printed in Great Britain

\title{
Toxicology of the Herbicide Dichlobenil (2,6-Dichlorobenzonitrile) and its Main Metabolites
}

\author{
H. VAN GENDEREN \\ Institute of Veterinary Pharmacology and Toxicology, University of Utrecht, \\ Utrecht, The Netherlands \\ and \\ G. J. VAN EsCH \\ National Institute of Public Heallh, Utrecht, The Netherlands
}

(Received 29 January 1968)

\section{SUMMARY}

A review of the toxicology of dichlobenil presents the results of acute tests in rats, mice and rabbits, short-term tests in rats, pigs and rabbits, long-term and reproduction studies in rats and a test for teratogenicity in mice. The compound is more toxic on acute administration to rabbits than to rats, but this difference in sensitivity is not apparent in short-term tests. A single lethal dose in the rabbit produces liver necrosis, but enzyme studies seem to indicate that sublethal doses cause little or no liver damage. The formation of phenolic metabolites has been demonstrated in both rats and rabbits. Various criteria show that these substituted phenols are active uncouplers of oxidative phosphorylation. The possible connexion between the liver necrosis found in the rabbit and the uncoupling action of the metabolites of dichlobenil is discussed.

\section{Introduction}

The herbicidal properties of dichlobenil (2,6-dichlorobenzonitrile; Casoron 133*) have been reported by Koopman \& Daams (1960), Barnsley (1960), Barnsley \& Rosher (1961), Daams \& Barnsley (1961) and Daams (1965). In view of its use as a weedkiller and antisprouting agent in potatoes, part of the toxicological work was started in the Netherlands' National Institute of Public Health with the study programme of The Food and Drug Administration (1959) as a guide. During this toxicological study it was observed that rabbits were much more sensitive than rats to acute exposure. This prompted studies on metabolism and mode of action, mainly carried out by the Institute of Veterinary Pharmacology and Toxicology in collaboration with the Philips Duphar Research Laboratories at Weesp, The Netherlands.

\section{Material}

Pure 2,6-dichlorobenzonitrile is a colourless crystalline substance, melting at $145-146^{\circ} \mathrm{C}$ and with a vapour pressure at $20^{\circ} \mathrm{C}$ of $5 \times 10^{-4} \mathrm{~mm} \mathrm{Hg}$. Its solubility in water is $18 \mathrm{ppm}$ at $20^{\circ} \mathrm{C}$. The pure compound was used for these studies.

-Trade Mark of N.V. Philips Duphar, Amsterdam. 


\section{Acute toxicity tests}

The acute oral toxicity of dichlobenil to rats and rabbits has been determined by Arnoldussen, Verschuuren \& van Esch (1963) and oral and intraperitoneal tests in mice have been carried out in the Philips Duphar Research Laboratories (Offringa, 1962). For rats of both sexes, the acute oral $\mathrm{LD}_{50}$, calculated by the method of Litchfield \& Wilcoxon (1949), was $4500 \mathrm{mg} / \mathrm{kg}$, compared with only $270 \mathrm{mg} / \mathrm{kg}$ for rabbits and $2100 \mathrm{mg} / \mathrm{kg}$ for mice. The intraperitoneal $\mathrm{LD}_{50}$ was found, in female mice only, to be $600 \mathrm{mg} / \mathrm{kg}$.

In the rats the cause of death was not established, but both liver and kidneys showed signs of damage. In the rabbits the main effect was the development of centrilobular liver necrosis. At a lethal oral dose of $400 \mathrm{mg} / \mathrm{kg}$, the animals appeared normal or slightly depressed during the first $6 \mathrm{hr}$ and died 12-24 hr after administration of the compound (J. H. Koeman, J. A. W. Brak and G. H. Veenendaal, unpublished report 1965).

\section{Short-term feeding tests}

In a programme of short-term tests in rats, pigs and rabbits (van Esch \& Arnoldussen, 1961; van Esch \& Verschuuren, 1964), groups of 10 male and 10 female rats were fed for 12 wk on $0,50,100,200,300$ or $500 \mathrm{ppm}$ dichlobenil, groups of two male (castrated) and two female pigs were given dietary levels of $0,20,50$ or $100 \mathrm{ppm}$ for $26 \mathrm{wk}$ and groups of five male and five female rabbits received $0,20,100$ or $500 \mathrm{ppm}$ for $12 \mathrm{wk}$. In addition, groups of 15 male rabbits were fed $0,10,20,50,500$ or $1000 \mathrm{ppm}$ for $12 \mathrm{wk}$. Organ weights were determined for liver, kidneys, spleen and heart in all species, and in addition for thymus, pituitary, thyroid, adrenals, pancreas, uterus, ovaries and testicles in the rats and rabbits, for lungs in the pigs only and for prostate in the rats only. Histopathological studies were made of all these organs and also of the thyroid, adrenals, pituitary, ovaries and stomach of the pigs.

An occasional increase or decrease, significantly different from the control animals, did occur at a probability of $5 \%$ (test of Wilcoxon), as could be expected in a large series of determinations. Some of these were not considered to be related to the treatment, because of their isolated occurrence at an intermediate dose level without a uniform dose-response relationship. For instance, a decrease in body weight in male rats receiving $50 \mathrm{ppm}$ dichlobenil or $300 \mathrm{ppm}$ was significant ( $\mathrm{P}=0.05$, Wilcoxon) at wk 6 but not at the end of the test, there was a slight increase in erythrocyte count in males on $200 \mathrm{ppm}$ and in the leucocyte and differential white cell counts in rats on $500 \mathrm{ppm}$ and the percentage of pseudoeosinophilic cells was increased in male rabbits receiving 50 or $500 \mathrm{ppm}$. There was also a scattered decrease in the testicular weight of rabbits, including some control animals, but the distribution was not significantly dose-dependent.

The main pathological effect in the rats and pigs on dietary levels of $100 \mathrm{ppm}$ or more was an increase in liver weight (of $114-130 \%$ compared with the controls). In the rats on $200 \mathrm{ppm}$ or more there was also an increase in kidney weight. Since no histopathological abnormalities were found, it was concluded that these increases up to the dose level of 500 ppm did not represent a true toxic effect, but were due to the unspecific burden placed on the organs by the dichlobenil treatment.

The effect on the liver was further studied in a special 80-day feeding test (den Tonkelaar, 1964) in which groups of 10 male and 10 female rats were given 0 or 5000 ppm dichlobenil. Liver function was tested regularly during the experiment. At day 71 of treatment half of the animals of each group were killed, the rest being maintained for a further 8 days on the control diet. It appeared that bromsulphalein (BSP) retention was increased at the 5000 
ppm level. There were no differences in the results of serum glutamic-pyruvic-transaminase and quinine-oxidase tests, but the activities of glucose 6-phosphatase and alkaline phosphatase were increased, the former particularly during the first part of the treatment. After termination of feeding with the dichlobenil-treated food at the end of the experiment, the BSP-retention and the activities of both glucose 6-phosphatase and alkaline phosphatase in serum dropped to near-control values. Histopathological examination of the liver at day 71 revealed changes in the centrilobular regions. These consisted of isolated groups of cells of increased size and abnormal density. Some pycnotic nuclei were present. These clusters were surrounded by normal liver cells. It is of interest to note that the abnormalities could not be found in the livers of the rats sacrificed 8 days after withdrawal of the dichlobenil.

Both the liver function tests and the histopathological examination point to a reversible effect at the 5000 ppm level in rats.

In male rabbits given $100 \mathrm{ppm}$ or $500 \mathrm{ppm}$ in the diet, the heart weight was decreased. This was not observed in the second rabbit study. In view of the sensitivity shown by rabbits in the acute toxicity tests, it is of interest that these animals, which were of the same strain, showed no liver involvement in the first short-term test and increases in liver weight only at levels of $500 \mathrm{ppm}$ and more in the second test. This was confirmed by a BSP-test made at the end of the first test on all the groups $(0,20,100$ and $500 \mathrm{ppm})$. No differences of statistical significance were found between sexes, indicating that the females dealt more efficiently with BSP than the males.

It is concluded from these short-term experiments that $50 \mathrm{ppm}$ is the dietary no-effect level for dichlobenil in rats, rabbits and pigs.

\section{Long-term feeding test in rats}

In a 2-yr study, groups of 20 male and 20 female Wistar rats were fed $0,20,50$ or $100 \mathrm{ppm}$ dichlobenil in the diet. When the animals died or were sacrificed the following organs were studied histopathologically: liver, kidneys, lung, heart, brain, leg muscle, pituitary, adrenals, gastro-intestinal tract, pancreas, bladder, thyroid, testis, salivary glands, spleen and uterus. There were no efiects on growth or mortality. In the pathological examination numerous abnormilities were found, as could be expected in old and moribund animals. Various forms of pneumonia and nephritis were frequently observed and many of the old animals had hyperplastic adrenals, thyroids and pituitaries, features which are common in our rat colony. There was no evidence of any response to dichlobenil treatment.

Several animals throughout the groups were found to have tumours, mainly mammary adenofibromata and lymphomata, which occur regularly in our rat colony. There was no dose response. Isolated cases were found of one lung sarcoma (20 ppm), one adrenal ganglioneuroma (20 ppm), one stomach epithelioma (control), two doubtful papillomas in the bladder (control and $100 \mathrm{ppm}$ ), one leiomyoma and one fibroma in the uterus (50 ppm and $100 \mathrm{ppm})$, one uterine adenoma (50 ppm), one subcutaneous sarcoma (50 ppm) and one epithelial tumour in the testis $(20 \mathrm{ppm})$. No liver tumours were seen. It is concluded that there is no evidence of carcinogenic action by dichlobenil.

In this test no toxic effects were observed. Of particular note was the absence of any damage to the liver even at the highest (100 ppm) level of treatment.

\section{Reproduction studies in rats}

The same dietary levels were used in this test as in the 2-yr feeding study. At the age of 4 months, after about 3 months dichlobenil feeding, ten pairs from each group were mated 
and, after weaning, the offspring (first litter) were fed the same dietary level of dichlobenil as their parents. From these $\left(F_{1}\right)$ animals, groups were taken for further study and for production of two $F_{2}$-generation litters. The $F_{1}$ generation was observed for 32 wk. Reproduction efficiency was judged on the number of females with litters, the total number of young after 1,5 and 21 days and the body weight of the group after 21 days. During the experiment, growth and blood composition, and at termination organ weights and histopathology were studied, both in the parent and $F_{1}$ generations.

There was some growth retardation in the 50 and $100 \mathrm{ppm}$ groups, particularly in the $F_{1}$ generation, but no haematological changes or histopathological abnormalities relevant to the treatment were recorded. In the $20 \mathrm{ppm}$ group, females of the parent generation and $F_{1}$ males showed a slight but significant increase in liver weight relative to body weight, but the difference disappeared when liver weight was expressed as a percentage of heart weight. Some increase in the weight of testicles in the $50 \mathrm{ppm}$ group and in liver and kidney weights at $100 \mathrm{ppm}$ were recorded in the $F_{1}$ generation. The breeding results of the $F_{1}$ generation were better than those of the parent generation. There were no clear differences in reproduction between control, 20 and $50 \mathrm{ppm}$ groups in the two generations. In the $100 \mathrm{ppm}$ groups there were fewer animals with litters, but there was no difference in the litter size. It appears, therefore, that dichlobenil has no influence on reproduction at dietary levels of $50 \mathrm{ppm}$ or below, but in this experiment growth inhibition occurred at $50 \mathrm{ppm}$ in the $\mathrm{F}_{1}$ generation.

The toxicological no-effect level established by this test was thus $20 \mathrm{ppm}$.

\section{Teratogenic study in mice}

Dichlobenil was administered orally to a group of 33 pregnant mice of the Swiss strain in a dose of $60 \mathrm{mg} / \mathrm{kg}$ daily from day 3 to 14 of pregnancy. A control group of 32 mice was treated at the same time with the vehicle. The animals were sacrificed on day 21 of pregnancy and the uterine contents were examined.

No differences between the treated and control groups were observed with regard to the number of pregnancies at day 21 , total number of foetuses, litter size or percentage of dead foetuses.

\section{Action on the liver}

A further analysis of the action of dichlobenil on the liver of rabbits involved the determination of enzyme activities in blood serum (J. H. Koeman, J. A. W. Brak and G. H. Veenendaal, unpublished report 1965). Most of the experiments concerned the sorbitol-dehydrogenase (SDH) test in serum, because of the predominant occurrence of this enzyme in the liver. Fructose was used as the substrate and NADH as the hydrogen-donor (Asada \& Galambos, 1963). In some other experiments, iso-citric acid dehydrogenase and serum glutamic-oxaloacetic and glutamic-pyruvic transaminases have been estimated with essentially similar results.

The dose levels of dichlobenil used were between 200 and $400 \mathrm{mg} / \mathrm{kg}$ body weight, orally administered. Blood samples for the enzyme determinations were taken before and at regular intervals up to $36 \mathrm{hr}$ after treatment or until the animal's condition precluded sampling. The results of these tests were remarkable; either there occurred a large increase in the serum activity of the enzymes and the rabbit died, or there was little or no increase and the animal remained alive. The findings with the SDH test are summarized in Table 1 and a few typical results are given in Fig. 1. Apparently, in this case, enzyme release seems to give ar all-or-nothing kind of response. 
Table 1. Sorbitol-dehydrogenase activity in rabbit serum* within $36 \mathrm{hr}$ of acute oral administration of dichlobenil

\begin{tabular}{cccc}
\hline $\begin{array}{c}\text { Dose } \\
(\mathrm{mg} / \mathrm{kg})\end{array}$ & $\begin{array}{c}\text { No. of } \\
\text { rabbits }\end{array}$ & Survival & $\begin{array}{c}\text { Mean SDH activity } \\
(\mu \text { moles/ml/hr) and } \\
\text { range of maximum } \\
\text { activity }\end{array}$ \\
\hline 0 & $22 \dagger$ & & $0 \cdot 5(0 \cdot 07-1 \cdot 4)$ \\
200 & 4 & $4 / 4$ & $1 \cdot 3(0 \cdot 2-4 \cdot 4)$ \\
250 & 2 & $2 / 2$ & $2 \cdot 5(2 \cdot 1-2 \cdot 9)$ \\
270 & 6 & $6 / 6$ & $0 \cdot 7(0 \cdot 5-0 \cdot 9)$ \\
400 & 2 & $2 / 2$ & $7 \cdot 6(2 \cdot 1-13)$ \\
400 & 8 & $0 / 8$ & $52(10-104)$ \\
\hline
\end{tabular}

*The rabbits used in this experiment were of a different strain from those used for the LD determination and survival figures indicate that they may have been less sensitive. In addition, the frequent blood sampling may have influenced the sensitivity.

†Determinations carried out on test animals prior to treatment.

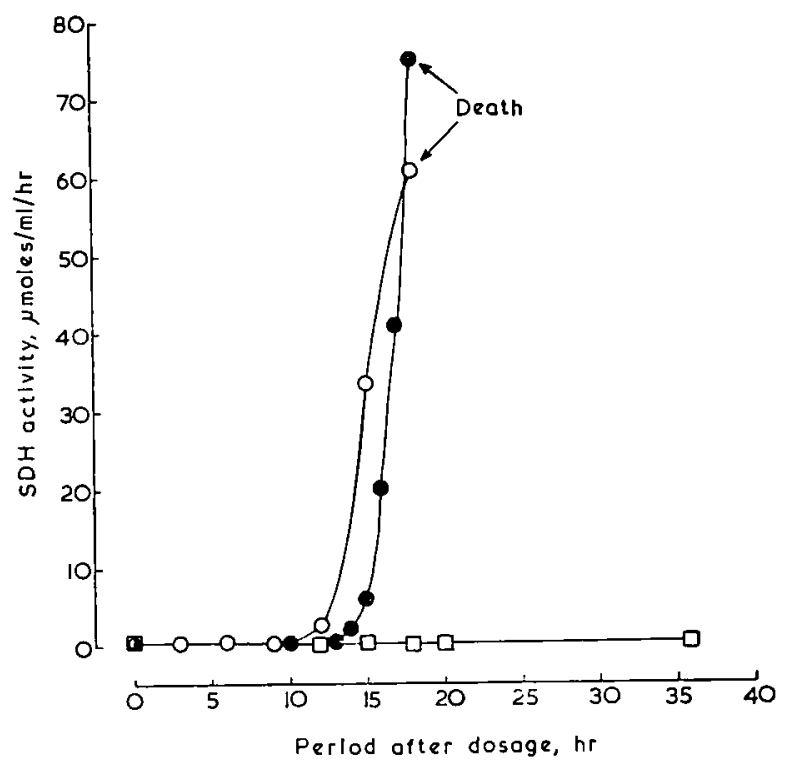

FIG. 1. Sorbitol-dehydrogenase activity in the serum of four rabbits after oral administration of dichlobenil at dose levels of $270 \mathrm{mg} / \mathrm{kg}$ (mean activity in two animals, $\square$ ) or $400 \mathrm{mg} / \mathrm{kg}$ (individual results for two animals, $O$ and $\bullet$ ).

In another series of experiments in rabbits (den Tonkelaar, Kroes \& van Esch, 1967) the BSP test was used (25 mg BSP, sampling of blood from the ear after $18 \mathrm{~min}$ ). Oral administration of dichlobenil in a dose of $250 \mathrm{mg} / \mathrm{kg}$ increased BSP retention in two out of three animals. This may have been the expression of an unspecific effect on the liver, not resulting in damage but interfering to some extent with the uptake of BSP by the liver. 


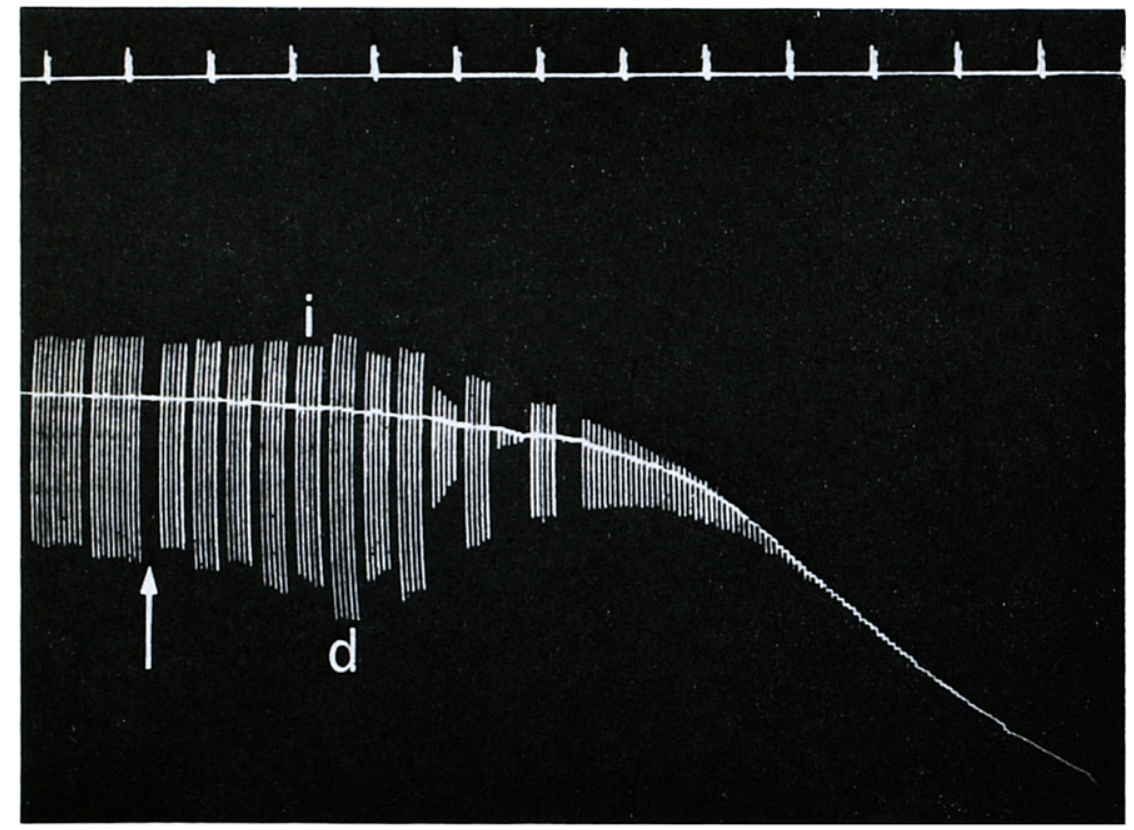

FIG. 2. Effect on isolated rat-diaphragm preparation of addition (arrowed) of 3-hydroxydichlobenil ( $55 \mu$ moles $/ 50 \mathrm{ml}$ organ bath). One stimulation $/ 4 \mathrm{sec}$ supramaximally, with alternate groups of indirect stimulations on the phrenic nerve (i) and direct stimulation on the muscle (d). Time signal $1 / \mathrm{min}$. An initial phase of twitch-potentiation is followed by a decrease in the contractions. The contractions after indirect stimulation disappear first, and the experiment is continued with only direct stimulation. Gradually a contracture develops. 


\section{Metabolism}

The metabolism of dichlobenil was studied in dogs, rats and rabbits with ${ }^{14} \mathrm{C}$-labelled preparations (Griffiths, Moss, Rose \& Hathway, 1966; Wit \& van Genderen, 1966a). The radioactivity was almost entirely eliminated within 4 dalys, mainly as more polar metabolites in the urine. Oral administration to rabbits caused an increased urinary excretion of glucuronides and ethereal sulphates. There was also an indication of mercapturic acid formation. In the urine of both rats and rabbits, conjugates of 3- and 4-hydroxy-2,6dichlorobenzonitriles could be identified as the major metabolites.

Griffiths et al. (1966) found that after administration of a small dose to rats, $41.7 \%$ and $4.0 \%$ of the radioactivity excreted in the urine was in the form of the 3-hydroxy and 4hydroxy derivatives respectively (of a total recovery of $81 \%$ ).

Wit \& van Genderen (1966a), using higher doses, obtained a recovery in rats of $22 \%$ of the dose in the form of the 3-hydroxy and $9 \%$ as the 4-hydroxy derivative. In rabbits, they found $23 \%$ and $2 \%$ of the dose respectively. Hydrolysis of the nitrile group is only a minor metabolic pathway. This is in agreement with the difficulty of hydrolysing this group under alkaline and acid conditions due to steric hindrance.

\section{Toxicological properties of the phenolic metabolites}

The chemical structure of the metabolites is closely relited to the structure of phenols which uncouple oxidative phosphorylation, such as ioxynil (3,5-diiodo-4-hydroxybenzonitrile) (Wain, 1963).

The acute oral $\mathrm{LD}_{50}$ of 3-hydroxydichlobenil for male micc is $1330(750-2370) \mathrm{mg}, \mathrm{kg}$. In the case of the 4-hydroxy derivative, two mice out of five were killed with $1420 \mathrm{mg} / \mathrm{kg}$ (O. R. Offringa, personal communication 1966). The intraperitoneal $L_{50}$ in female mice is $51 \mathrm{mg} / \mathrm{kg}(46-56)$ for the 3-hydroxy and $83 \mathrm{mg} / \mathrm{kg}$ (79-83) for the 4-hydroxy compound. It is noteworthy that death and rigor mortis usually occurred within 5 min of the intraperitoneal injection (A. de Zwaan, unpublished report 1966).

In a 3-month feeding study in rats, the no-effect level of the 3-hydroxy compound was $300 \mathrm{ppm}$. Neither at this level nor at the higher dose levels was the liver affected with regard to size, clinical chemistry or histopathology (Kemp, 1967).

The action of these phenols was further studied in the following experiments:

(a) Respiration of bakers' yeast. 2,4-Dinitrophenol interferes in a characteristic way with the aerobic assimilation of glucose by starved yeast cells. The oxygen uptake after addition of a small amount of glucose is prolonged, indicating that the cells oxidize glucose without assimilation (Wit \& van Genderen, 1966b). Both 3- and 4-hydroxydichlobenil have the same effect and about the same activity as 2,4-dinitrophenol.

(b) ATP-ase induction in isolated mitochondria. In isolated rat-liver mitochondria, both the 3- and 4-hydroxy compounds induced ATP-ase activity over a wide range of concentrations depending on $\mathrm{pH}$ in a manner similar to that of 2,4-dinitrophenol (Wit \& van Genderen, 1966b). At pH 7, the 3-hydroxy derivative is active at a concentration of $10^{-5} \mathrm{M}$ and the 4-hydroxy at $2 \times 10^{-6} \mathrm{M}$. Dichlobenil itself is inactive. In a separate group of experiments (A. de Zwaan, unpublished report 1966), rabbit- and rat-liver mitochondria were compared, but there was no difference in their sensitivity to the ATP-ase-inducing effect of 2,4-dinitrophenol or 3-hydroxydichlobenil.

(c) Contraction of the isolated rat diaphragm. Uncoupling angents produce a characteristic contracture in most striated muscles. The activity of the 3- and 4-hydroxy derivatives has been tested (J. G. Wit and J. M. M. van den Bercken, personal communica- 
tion in 1966), on the isolated diaphragm of the rat (Barnes, Duff \& Threlfall, 1955) and compared with that of 2,4-dinitrophenol. Both compounds produce contracture, and an example of a recording is reproduced in Fig. 2. These effects were visible with concentrations of from $3 \mu$ moles $/ 100 \mathrm{ml}$ organ bath. The potency was about equal to that of 2,4-dinitrophenol and, as in the case of the latter, the contracture also appeared in diaphragm preparations which, after depolarization in a potassium chloride solution, had recovered from the depolarization contracture.

(d) Single beating heart-cells in tissue culture. 2,4-Dinitrophenol stops the beating of isolated heart cells from newborn rats in tissue culture.(Mulder \& Wit, 1966). The beating can be restored by addition of ATP or oligomycin. The latter enables the cell to utilize the ATP from the extra-mitochondrial glycolysis. It appeared that 3- and 4hydroxydichlobenil had the same effect as 2,4-dinitrophenol in concentrations of 3.0 $\mu \mathrm{mole} / \mathrm{ml}$ medium.

\section{Discussion}

It was concluded that $20 \mathrm{ppm}$ dichlobenil in the diet was the lowest toxicological no-effect level in the short- and long-term feeding studies. At $50 \mathrm{ppm}$, growth inhibition occurred in second generation rats, and at higher levels hypertrophy of the liver and kidneys was found. Rats were able to support a dose level of 5000 ppm in a 10 -wk feeding test. During this treatment liver function was depressed, increased activities of serum enzymes gave evidence of damage to parenchymatous tissues and there were histopathological changes in the liver. Further tests, after withdrawal of the dichlobenil for $1 \mathrm{wk}$, indicated that the effect of dichlobenil on the liver is reversible. In the long-term experiment, no liver tumours were found and there was no evidence of carcinogenic action by dichlobenil at any other sites. In contrast to the findings in acute tests, rabbits were no more sensitive than rats in feeding tests.

The first hypothesis to explain the effect on the liver in the acute exposure of rabbits to lethal doses of dichlobenil was that this compound might interfere with sulphydryl groups. The indications or mercapturic acid excretion in the urine do not give much support to that idea, but the possibility of a reaction with thiol groups is not excluded.

A more likely mode of action was suggested when the metabolism studies demonstrated the formation of phenols as major metabolites (3- and 4-hydroxydichlobenil). These compounds were shown to be very active uncouplers of oxidative phosphorylation. However, toxicological experience with well-known uncouplers such as 2,4-dinitrophenol and 2,4dinitro-o-cresol does not point to liver damage as a cause of death in acute poisoning. Also, after intraperitoneal injection of 3- or 4-hydroxydichlobenil in mice, death ensued too quickly to be due to liver poisoning. In subacute treatment with uncoupling agents, liver involvements have often been noted. It is very likely that in cases of poisoning, death is due to failure of the heart or respiration and that the liver is protected by its capacity to conjugate these phenols. The increased excretion of glucuronides and ethereal sulphates shows that the phenolic metabolites of dichlobenil are actively conjugated after their formation. The 25-fold increase in the toxicity of the 3-hydroxy compound for mice when given intraperitoneally, compared with oral administration, also points to an efficient detoxication by the liver.

A probable explanation of the effect of dichlobenil on the rabbit liver is that this nonpolar compound itself has little biological action but that it is efficiently taken up by the liver and transformed into the active phenols at the very site where their uncoupling action 
affects the metabolism of the liver cell. The formation of the phenols and their inactivation by conjugation take place in the liver. Hydroxylation is independent of available ATP, but for the conjugation the active participation of ATP is necessary. It seems likely that when the concentration of the free phenols in the liver cells rises above a certain critical concentration, the uncoupling will interfere with ATP production to the extent that conjugation cannot keep pace with hydroxylation. Thereafter the concentration of the phenols will rise sharply with complete suppression of conjugation. There will be no more ATP and this may lead to loss of integrity of the cell and explain the necrosis of the liver. In this connexion the study of Mölbert (1957) should be mentioned: only 20 min after injection of 2,4-dinitrophenol into the portal vein of rats, electron-microscopic examination revealed necrotic changes in the liver cells.

This hypothesis might also explain the all-or-nothing type of liver reaction shown in the enzyme release experiments. If the critical concentration of the free phenols is not attained, there will be no notable developments in the liver, except perhaps a less efficient use of the energy from respiration. The action of dichlobenil brings to mind the mechanism of a trapdoor. This trapdoor effect does not occur with the well-known hepatotoxic agents, such as carbon tetrachloride, which cause liver damage and enzyme release over a wide range of sublethal dose levels.

This hypothesis does not explain why rats are so much less sensitive to acute exposure than are rabbits. It was shown that isolated mitochondria of rat liver are as sensitive to uncoupling by 3-hydroxydichlobenil as are rabbit-liver mitochondria. It is possible that in rats the critical concentration of the free phenols is not attained. The biochemical pathogenesis of the liver lesion produced in the rat by high dose levels of dichlobenil may be entirely different from that in acute poisoning in the rabbit. This has been confirmed in a preliminary experiment by den Tonkelaar et al. (1967), who showed that at a dosage of $2.5 \mathrm{~g} / \mathrm{kg}$ in rats (which is far below the $\mathrm{LD}_{50}$ ) an increase occurred in the activities of serum glutamicpyruvic transaminase and quinine oxidase. The same applies to the feeding experiments in both rats and rabbits, where only "unspecific" liver effects appeared.

Acknowledgement-The veterinary pathologists H. H. Vink, R. Kroes and E. J. Ruitenberg of the National Institute of Public Health have been responsible for the pathological evaluation of the material from the toxicity tests. The subacute and long-term studies were carried out by $H$. G. Verschuuren and Miss A. M. Arnoldussen. The liver function tests were made by Dr. E. M. den Tonkelaar of the National Institute of Public Health and J. H. Koeman of the Institute of Veterinary Pharmacology and Toxicology. Dr. J. G. Wit and J. M. M. van den Bercken carried out the experiments with the isolated diaphragm.

We gladly acknowledge the contributions of R. A. Prins, D. Rosenberg, J. A. W. Brak, G. H. Veenendaal and A. de Zwaan during their study course in toxicology at the Institute of Veterinary Pharmacology and Toxicology. We appreciate the collaboration of the N.V. Philips Duphar, Amsterdam, during the course of our study.

\section{REFERENCES}

Arnoldussen, A. M., Verschuuren, H. G. \& van Esch, G. J. (1963). Various acute and short term toxicity investigations of dichlobenil. Report U4/63 Tox. National Institute of Public Health, Utrecht.

Asada, M. \& Galambos, J. T. (1963). Sorbitol dehydrogenase and hepatocellular injury: an experimental and clinical study. Gastroenterology 44, 578.

Barnes, J. M., Duff, J. I. \& Threlfall, C. J. (1955). The behaviour of mammalian striated muscle in the presence of 2,4-dinitrophenol. J. Physiol. Lond. 130, 585.

Barnsley, G. E. (1960). An assessment of the new herbicide 2,6-dichlorobenzonitrile. Fifth British Weed Control Conference, 1960.

Barnsley, G. E. \& Rosher, P. H. (1961). The relationship between the herbicidal effect of 2,6-dichlorobenzonitrile and its persistence in the soil. Weed Res. 1, 147. 
Daams, J. (1965). Das Verhalten von Dichlobenil in Boden und Pflanze. Z. PfKrankh. PflPath. PfSchutz, Sonderheft III, 139.

Daams, J. \& Barnsley, G. E. (1961). General herbicidal properties of 2,6-dichlorobenzonitrile. Proceedings of the European Weed Research Conference, Columa, Paris 1961, p. 60.

den Tonkelaar, E. M. (1964). Leverfunctieproeven bij toxicologisch onderzoek. Berichten uit het Rijks Instituut voor de Volksgezondheid, 229.

den Tonkelaar, E. M., Kroes, R. \& van Esch, G. J. (1967). Leverfunctietesten bij rat en konijn. Report 58/67 Tox. National Institute of Public Health, Utrecht.

Food \& Drug Administration (1959). 'Appraisal of the Safety of Chemicals in Foods, Drugs \& Cosmefics'. Edited \& published by the Association of Food and Drug Officials of the United States, Austin 1, Texas.

Griffiths, M. H., Moss, J. A., Rose, J. A. \& Hathway, D. E. (1966). The comparative metabolism of 2,6dichlorothiobenzamide (Prefix) and 2,6-dichlorobenzonitrile in the dog and rat. Biochem. J. 98, 770.

Kemp, A. (1967). Dietary administration of 3-hydroxy-2,6-dichlorobenzonitrile (3-OH) in male and female rats for 12 weeks. Report nr. 56645/3/67 N.V. Philips-Duphar.

Koopman, H. \& Daams, J. (1960). 2,6-Dichlorobenzonitrile: a new herbicide. Nature, Lond. $186,89$.

Litchfield, J. T. \& Wilcoxon, F. (1949). A simplified method of evaluating dose-effect experiments. J. Pharm. exp. Ther. 96, 99.

Mölbert, E. (1957). Das elektronenmikroskopische Bild der Leberparenchymzelle nach histotoxischer Hypoxydose. Beitr. pathol. Anat. 118, 203.

Mulder, A. H. \& Wit, J. G. (1966). The inhibitory action of 2,6-dichloro-3-hydroxybenzonitrile and 2,6dichloro-4-hydroxybenzonitrile on the beating of heart cells in tissue culture. Antagonism of oligomycin. Biochim. biophys. Acta 128, 391.

Offringa, O. R. (1962). Survey of the acute toxicity of dichlobenil. Report nr. 56648/65/62, N.V. PhilipsDuphar.

van Esch, G. J. \& Amoldussen, A. M. (1961). Semichronic investigations with rats regarding the toxicity of dichlobenil. Report Tox. 116/6I ; Semichronic investigations with pigs regarding the toxicity of dichlobenil. Report Tox. 137/61. National Institute of Public Health, Utrecht.

van Esch, G. J. \& Verschuuren, H. G. (1964). Investigations as to the toxicity of H133, including a chronic experiment with rats. Report 54/64 Tox. National Institute of Public Health, Utrecht.

Wain, R. L. (1963), 3:5-Dihalogeno-4-hydroxybenzonitriles: New herbicides with molluscicidal activity. Nature, Lond. 200, 28.

Wit, J. G. \& van Genderen, H. (1966a). Metabolism of the herbicide 2,6-dichlorobenzonitrile in rabbits and rats. Biochem. J. 101, 698.

Wit, J. G. \& van Genderen, H. (1966b). The monophenolic metabolites of the herbicide 2,6-dichlorobenzonitrile in animals as uncouplers of oxidative phosphorylation. Biochem. J. 101, 707. 